
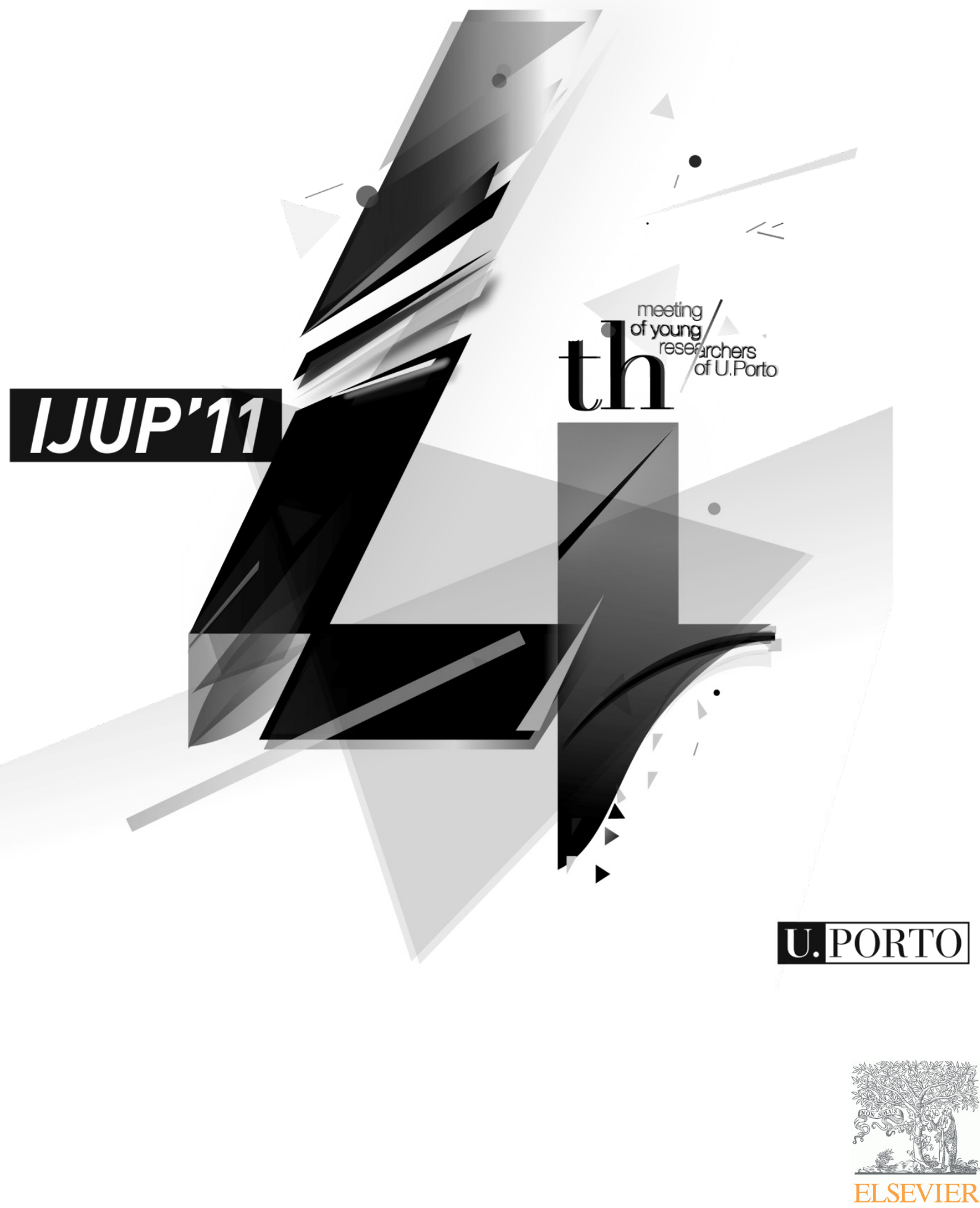



\section{IJUP Committee}

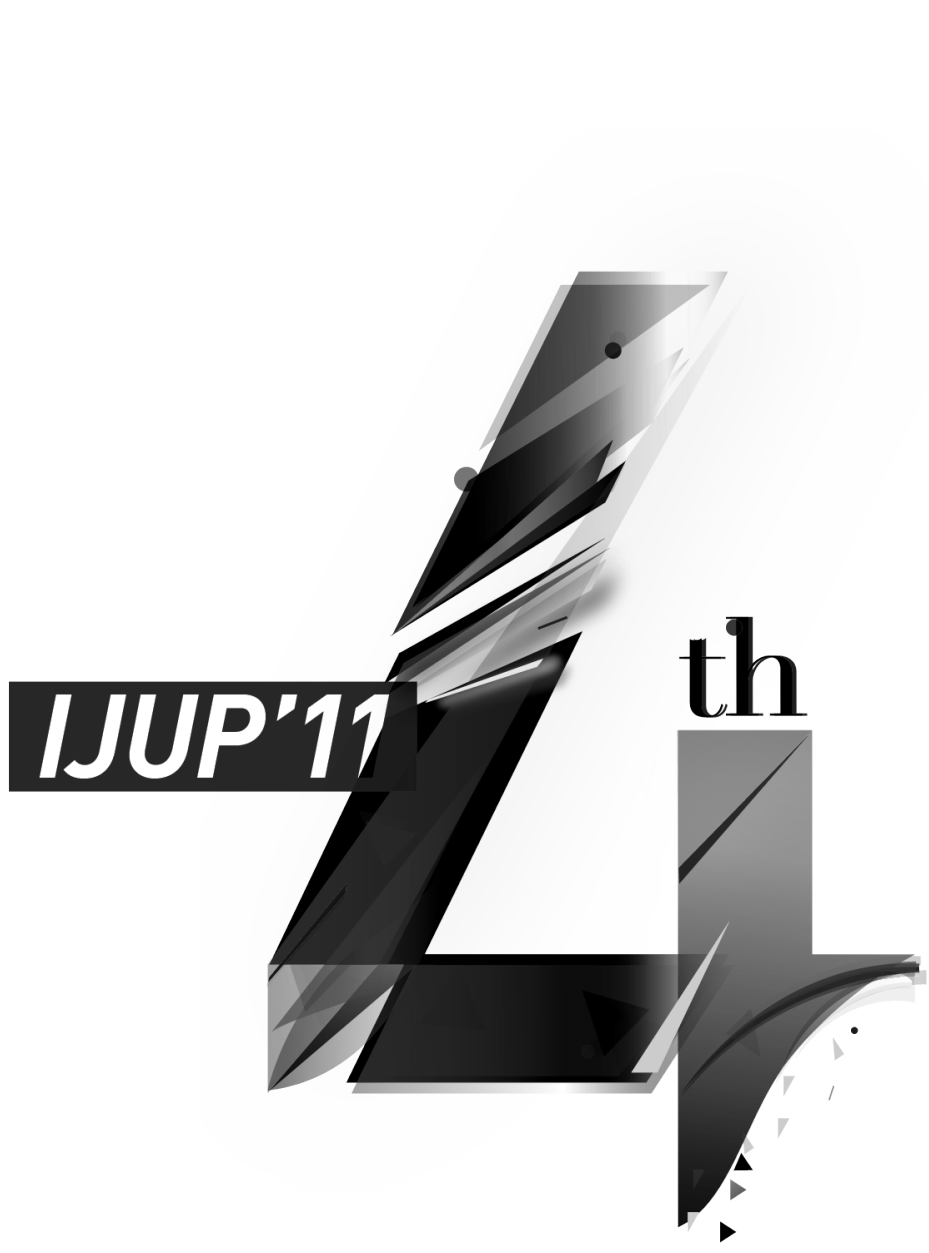

Adrián Silva

Aurora Teixeira

Elisa Keating

Filipe Magalhães

Georgina Silva

Gonçalo Furtado

Graciela Machado

Hélder Bastos

Helena Madureira

Jorge Gonçalves

Jorge Teixeira

José Rodrigues Lima

Laura Oliveira

Luís Miguel Madeira

M. a Paula Santos

Manuela Aguiar

Marcela Segundo

Maria José Oliveira

Patrícia Antunes

Paula Coelho

Pedro Sousa Gomes

Rita Faria

Sofia Rodrigues

Vitor Vasconcelos 



\section{Program}

\section{Thursday, February $17^{\text {th }}$}

09:00-09:30

9:30-11:00

11:00-11:30

$11: 30-12: 30$

$12: 30-14: 00$

14:00-15:30

15:30-17:00

$17: 00-18: 30$
Registration

Parallel Oral Sessions I

A1 - Biological, Environmental \& Health Sciences I

p. 7

A2 - Biological, Environmental \& Health Sciences II

p. 15

A3 - Literature \& Language Sciences

A4 - Engineering I

p. 23

p. 31

p. 39

Welcome Session - A1

Poster Session \& Coffee Break

Lunch Break

Parallel Oral Sessions II

A1 - Biological, Environmental \& Health Sciences III

p. 47

A2 - Biological, Environmental \& Health Sciences IV

p. 55

A3 - Psychology \& Education Sciences I

p. 63

A4 - Engineering II

p. 71

A5 - Applied Physics

p. 79

Poster Session \& Coffee Break

Parallel Oral Sessions III

A1 - Biological, Environmental \& Health Sciences V

p. 87

A2 - Biological, Environmental \& Health Sciences VI

p. 95

A3 - Geography, Sociology \& Economics I

A4 - Engineering III

p. 103

A5 - Law and Criminological Sciences

p. 111

p. 117

\section{Friday, February $18^{\text {th }}$}

\section{9:00-10:30}

10:30-11:00

$11: 00-12: 30$

$12: 30-14: 00$

$14: 00-15: 30$

$15: 30-17: 00$

17:00-18:30

\section{Parallel Oral Sessions IV}

A1 - Biological, Environmental \& Health Sciences VII

p. 125

A2 - History, Visual \& Cultural Studies I

p. 133

A3 - Communication Sciences II

A4 - Engineering IV

A5 - Engineering $V$

p. 139

p. 147

p. 155

A6 - Architecture

p. 163

Poster Session \& Coffee Break

Parallel Oral Sessions V

A1 - Biological, Environmental \& Health Sciences VIII p. 171

A2 - History, Visual \& Cultural Studies II

p. 179

A3 - Psychology \& Education Sciences II

p. 185

A4 - Engineering VI

A5 - Sport Sciences I

p. 193

p. 201

A6 - Agronomy \& Chemistry I

p. 211

Lunch Break

A1 - Workshop "The Researcher's Checklist"

Poster Session \& Coffee Break

Parallel Oral Sessions VI

A1 - Biological, Environmental \& Health Sciences IX

p. 219

A2 - Communication Sciences III

p. 225

A3 - Agronomy \& Chemistry II

p. 233

A4 - Geography, Sociology \& Economics II

p. 241

A5 - Sport Sciences II 


\section{Abstract Book Index}

\section{Oral Sessions}

Parallel Oral Sessions I

Thursday, February $17^{\text {th }}$

p. 7

Parallel Oral Sessions II

Thursday, February $17^{\text {th }}$

p. 47

Parallel Oral Sessions III

Thursday, February $17^{\text {th }}$

p. 87

Parallel Oral Sessions IV

Friday, February $18^{\text {th }}$

p. 125

Parallel Oral Sessions V

Friday, February $18^{\text {th }}$

p. 171

Parallel Oral Sessions VI

Friday, February $18^{\text {th }}$

p. 219

\section{Posters}

Posters I

Thursday, February $17^{\text {th }}$

p. 259

Posters II

Friday, February $18^{\text {th }}$

p. 405

Index

p. 553 


\title{
Protective Effect of Physical Activity on Dissatisfaction with Body Image in Children - A Cross-sectional Study
}

\author{
M. Gaspar ${ }^{1}$, T. Amaral ${ }^{1}$, B. Oliveira ${ }^{1}$, and N. Borges ${ }^{1}$ \\ ${ }^{1}$ Faculdade de Ciências da Nutrição e Alimentação, Universidade do Porto, Portugal.
}

An accurate body image perception is crucial for the way children and adolescents develop a healthy relationship with their bodies and food intake behavior [1]. Some evidence also exist showing that regular physical activity and sport have a beneficial effect on the way children and adolescents perceive their body image [2,3]. Nevertheless, the association between physical activity and body image dissatisfaction has not been yet properly quantified. The aim of the present work was to evaluate the frequency of dissatisfaction with body image among secondary school students and to examine the association between the physical activity and Body Mass Index (BMI) with image dissatisfaction.

This is a cross-sectional study conducted in a Porto high school, in which 234 children of both sexes, aged between 10 and 17 years were evaluated. Dissatisfaction with body image was assessed by Collins' Child Figure Drawings for pre-adolescents and adolescents [4]. The degree of dissatisfaction with body image (FID) was calculated as discrepancy between the "ideal figure" and the "perceived figure". The Baecke questionnaire was applied to determine the Habitual Physical Activity Index (HPAI) of each participant [5].

Girls were more dissatisfied than boys with their body image (68.1\% vs. 52.9\%). A high proportion of students of both genders and age groups presented a distorted body image stating that their "perceived figure" was bigger than the "ideal figure". A moderate correlation was found between the FID and BMI percentile in both genders (boys: $r=.698, p<.001$, girls: $r=$ $.582, p<.001)$. High levels of physical activity were associated with a protective effect on dissatisfaction with body image, $O R=.38,95 \%$ CI $[.16, .87]$ for $3^{\text {rd }} v s 1^{\text {st }}$ quartile of HPAI; OR $=.29,95 \%$ CI $[.12, .86]$, for $4^{\text {th }} v s 1^{\text {st }}$ quartile of HPAI, both adjusted for BMI and gender.

In conclusion, body image dissatisfaction increases directly with BMI percentiles in both genders and physical activity has a protective effect on distortion of body image.

\section{References:}

[1] Strauss, R.S. (1999). Self-reported weight status and dieting in a cross-sectional sample of young adolescents: National Health and Nutrition Examination Survey III, Archives of Pediatrics and Adolescent Medicine, 153(7), 741-7.

[2] Kircaldy, B.D., Shephard, R.J., \& Siefen, R.G. (2002). The relationship between physical activity and self-image and problem behavior among adolescents, Social Psychiatry and Psychiatric Epidemiology, 37(11), 544-50.

[3] Moreno, J.A., Cervelló, E. and Moreno, R. (2008). Importancia de la práctica físico-deportiva y del género en el autoconcepto físico de los 9 a los 23 años, International Journal of Clinical and Health Psychology, 8(1), 171-183.

[4] Collins, M.E. (1991). Body figure perceptions and preferences among preadolescent children, The International Journal of Eating Disorders, 10(2), 199-208.

[5] Baecke, J.A.H., Burema, J., and Frijters, J.E.R. (1982). A short questionnaire for the measurement of habitual physical activity in epidemiological studies, The American Journal of Clinical Nutrition, 36(5), 936-942. 